\title{
The relative risk and its distribution of endocrine disrupting chemicals, pharmaceuticals and personal care products to freshwater organisms in the Bohai Rim, China
}

\author{
Meng Zhang a,b ${ }^{\mathrm{a}}$, Yajuan Shi ${ }^{\mathrm{a}, *}$, Yonglong Lu ${ }^{\mathrm{a}, \mathrm{b}, * *}$, Andrew C. Johnson ${ }^{\mathrm{c}}$, Suriyanarayanan Sarvajayakesavalu ${ }^{\mathrm{d}}$, \\ Zhaoyang Liu ${ }^{\mathrm{a}, \mathrm{b}}$, Chao Su ${ }^{\mathrm{a}, \mathrm{b}}$, Yueqing Zhang ${ }^{\mathrm{a}, \mathrm{b}}$, Monika D. Juergens ${ }^{\mathrm{c}}$, Xiaowei Jin ${ }^{\mathrm{e}}$ \\ a State Key Laboratory of Urban and Regional Ecology, Research Center for Eco-Environmental Sciences, Chinese Academy of Sciences, Beijing 100085, China \\ ${ }^{\mathrm{b}}$ University of Chinese Academy of Sciences, Beijing 100049, China \\ ' Centre for Ecology \&' Hydrology, Maclean Building, Crowmarsh Gifford, Wallingford, Oxon OX 10 8BB, UK \\ d SCOPE (Scientific Committee on Problems of the Environment) Beijng Office, P.O. Box 2871, 18 Shuangqing Road, Haidian District, Beijing 100085, China \\ e China National Environmental Monitoring Center, Beijing 100012, China
}

\section{H I G H L I G H T S}

- Surfactants (LAS) and EDCs (NP and DEHP) posed greater risk than pharmaceuticals.

- Antibiotics showed higher risk to algae, invertebrates and the least risk to fish.

- Municipal sewage was considered to be the major source for pharmaceuticals' risk.

- The risk posed by LAS was significantly affected by wet and dry season change.

- Risk difference of LAS and ETM in the rivers was affected by elimination process.

\section{A R T I C L E I N F O}

\section{Article history:}

Received 31 October 2016

Received in revised form 1 March 2017

Accepted 2 March 2017

Available online 9 March 2017

Editor: Kevin V. Thomas

\section{Keywords:}

Pharmaceuticals

Personal care products

Endocrine disrupting chemicals

Risk ranking

Bohai coastal region

\section{G R A P H I C A L A B S T R A C T}

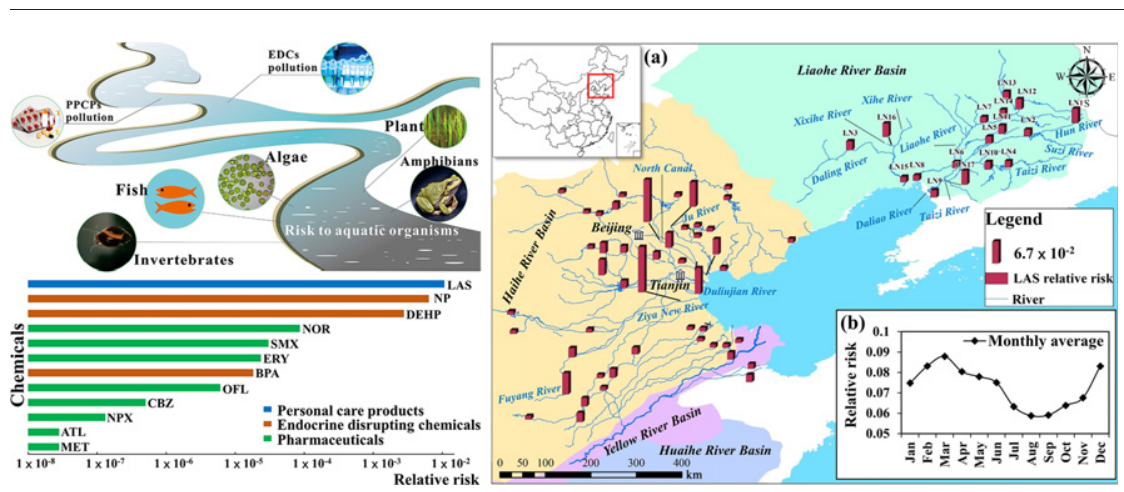

\section{A B S T R A C T}

In this study, the risks to aquatic organisms posed by 12 commonly detected pharmaceuticals and personal care products (PPCPs) and endocrine disrupting chemicals (EDCs) that are extensively used in Bohai coastal region of China were examined. These were linear alkylbenzene sulfonate (LAS), nonylphenol (NP), diethylhexyl phthalate (DEHP), norfloxacin (NOR), sulfamethoxazole (SMX), erythromycin (ERY), bisphenol A (BPA), ofloxacin (OFL), carbamazepine (CBZ), naproxen (NPX), atenolol (ATL) and metoprolol (MET). Their relative risk was ranked based on the proximity between the medians of the reported effect concentrations and measured river or lake water concentrations. The surfactants (LAS) and endocrine disrupting chemicals NP (a breakdown product of the surfactant nonylphenol polyethoxylate) and DEHP (a plasticizer) were identified as posing the greatest risk from this range of chemicals. LAS had a hundred-fold higher risk than any of the pharmaceuticals. The highest risk ranked pharmaceuticals were all antibiotics. Zinc $(\mathrm{Zn})$ and mercury $(\mathrm{Hg})$ were added to the comparison as representative heavy metals. $\mathrm{Zn}$ posed a risk higher than all the organics. The risk posed by $\mathrm{Hg}$ was less than the surfactants but greater than the selected pharmaceuticals. Whereas LAS and DEHP could cause harmful effects to all the wildlife groups, NP and BPA posed the greatest risk to fish. Antibiotics showed the highest risk

\footnotetext{
* Corresponding author.

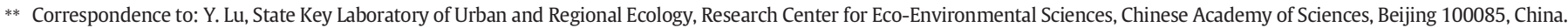
E-mail addresses: yajuanshi@rcees.ac.cn (Y. Shi), yllu@rcees.ac.cn (Y. Lu).
} 
to algae. Spatial and temporal distributions of PPCPs and EDCs were conducted for risk identification, source analysis and seasonal change exploration. Municipal sewage effluent linked to urban areas was considered to be the major source of pharmaceuticals. With regard to seasonal influence the risk posed by LAS to the aquatic organisms was significantly affected by wet and dry seasonal change. The dilution effects were the common feature of LAS and ERY risks. The difference in LAS and ERY risk patterns along the rivers was mainly affected by the elimination process.

(C) 2017 Elsevier B.V. All rights reserved.

\section{Introduction}

Pharmaceuticals and personal care products (PPCPs), including antibiotics, antiinflammatory drugs, antiepileptics, surfactants, detergents, disinfectants, fragrances and cosmetics (Boxall et al., 2012; Bu et al., 2013), are found in variety of environmental media (Boyd et al., 2003; Bendz et al., 2005; Petrovic et al., 2005; Hernando et al., 2006; Kasprzyk-Hordern et al., 2008; Santos et al., 2010). Endocrine disrupting chemicals (EDCs) have also been widely reported in freshwaters. Many of these chemicals discharged in wastewater are persistent or "pseudopersistent" (due to their continuous introduction into the environment) (Daughton and Ternes, 1999) and may generate potential negative impacts on aquatic organisms (De Garcia et al., 2014; Gaw et al., 2014). Sewage effluents and waste water treatment plants have been recognized as major sources of such chemicals arising from human activities in the aquatic environment (Daughton and Ternes, 1999; Kolpin et al., 2002; Rosi-Marshall and Royer, 2012).

China is the largest producer of active pharmaceutical ingredients of the world with an estimated production of about two million tons of pharmaceuticals in 2011, and a consumption of antibiotics of $>$ 180.000 tons/year (Zheng et al., 2012). China is also one of the top three countries with the largest personal care product consumption
(Liu and Wong, 2013). In addition, the issue of estrogenic disrupting compounds in waters around China from waste water plant effluents, agricultural fertilizers and fish farming wastes (Jiang et al., 2012; Xu et al., 2014) have also led to concerns over potential adverse impacts on wildlife and human health (Guillette et al., 1995; Jiang et al., 2012). The Bohai coastal region (including Beijing, Tianjin, Hebei, Shandong, Liaoning, Fig. 1) located in the Northern China, is one among the three most important economic zones in China (Guo et al., 2009; Yang et al., 2015). This region accounts for $5.4 \%$ of the whole area of China, but contains $18.5 \%$ of the country's population and contributes $25 \%$ of the national GDP. Thus, its waterways could be considered as representative of developed regions of China. However, the risks from chemicals such as PPCPs and EDCs in the Bohai Rim have received little attention due to the lack of environmental standards or guidelines. But given the worldwide knowledge available on the ecotoxicity of such compounds can we assess whether they pose a risk to the rivers of this developed and populous region of China?

The objectives of this study were:

- To identify which of the PPCPs and EDCs monitored in the Bohai Rim freshwater bodies posed the greatest risk to local aquatic wildlife

- To identify which wildlife groups were most at risk

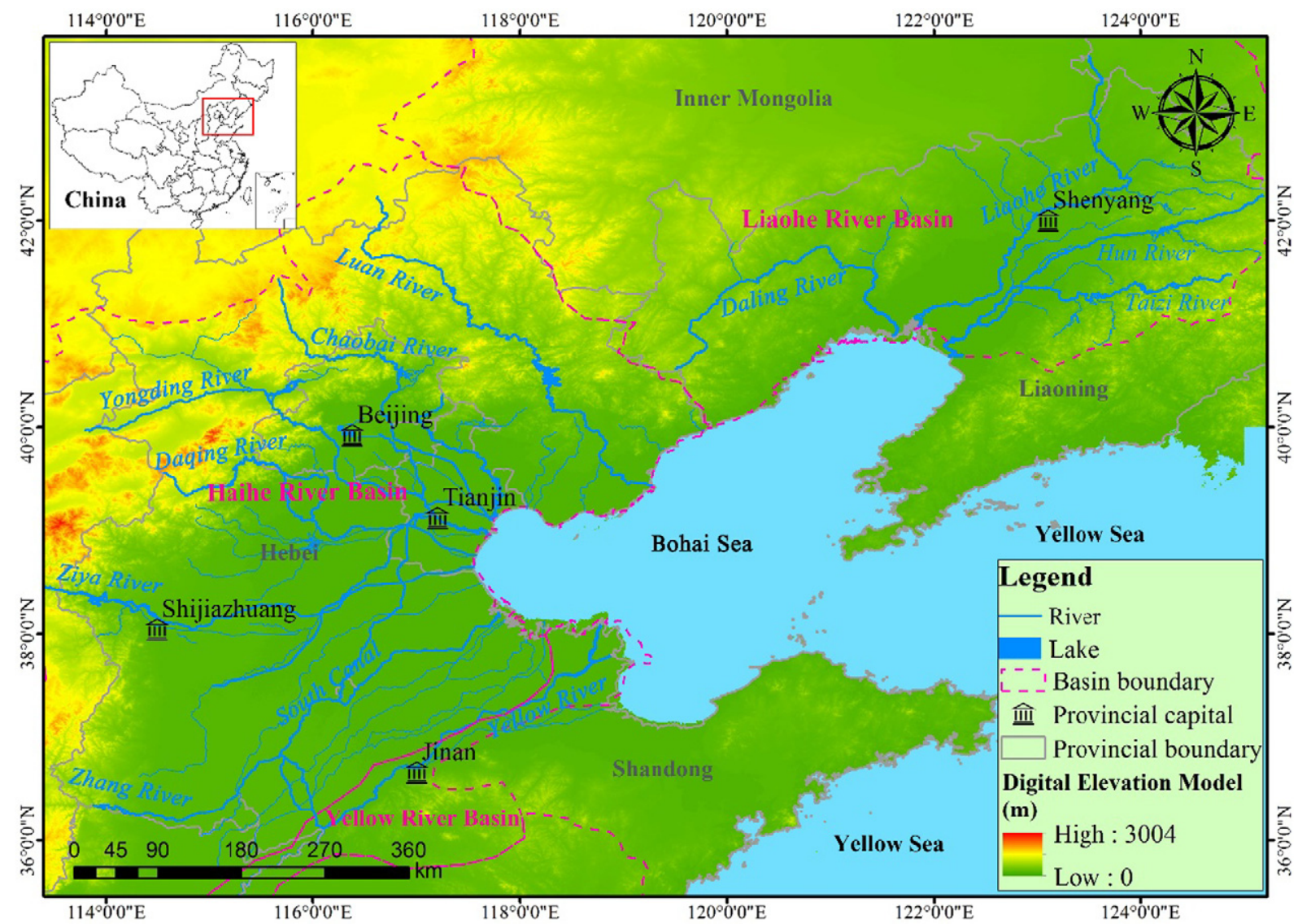

Fig. 1. Study area and water bodies with PPCPs and EDCs measurements. 
- To explore the temporal and spatial characteristics of PPCPs and EDCs risks

\section{Methods and ranking analysis}

\subsection{Study area, chemical selection and the collection of monitoring data}

The spatial area was limited to regions around the Bohai sea, which covers the economic centers of Beijing and Tianjin, and the provinces of Hebei, Shandong and Liaoning, known as Bohai coastal region or Bohai Rim (Fig. 1). The region is about $518,000 \mathrm{~km}^{2}$ with a population density of 671 people per square kilometer. Agricultural land is the dominant type in the region with the proportion of $71 \%$, followed by construction land (13.8). $>100$ rivers flow through this region and contribute 65 billion $\mathrm{m}^{3}$ of water to the Bohai sea. The Haihe River and Liaohe River Systems are the two main drainage systems in this region and from which most of the monitoring data was available for this study. Rapid but unbalanced urbanization and industrialization are taking place in the region, and Beijing and Tianjin are the two main economic centers here with population densities of 1311 and 1290 people per square kilometer respectively, (Fig. S1). Considering the close correlation between the contamination level and the development of urbanization and industrialization in China (Wang et al., 2008; Wang et al., 2012), the wildlife in this region will be highly exposed to environmental contamination. Information on the industrial and municipal waste water discharge and main industries of each city in the study area are provided in Table S1.

Monitoring data were available for atenolol (ATL), bisphenol A (BPA), carbamazepine (CBZ), diethylhexyl phthalate (DEHP), erythromycin (ERY), linear alkylbenzene sulfonates (LAS), metoprolol (MET), naproxen (NPX), nonylphenol (NP), norfloxacin (NOR), ofloxacin (OFL) and sulfamethoxazole (SMX) in the surface waters of Bohai coastal region. The Chemical Abstracts Service (CAS) Registry Number, main use/group, molecular formula and molecular structure of target PPCPs and EDCs are shown in Table S2. Zinc ( $\mathrm{Zn}$ ) and mercury (Hg) were selected to place these soluble organic contaminants in context to the risks from these well known metal contaminants. These two metals are frequently detected in the environment and are potentially hazardous to the environmental organisms (Delgado et al., 1993; Li et al., 2014; Liu et al., 2017).

Only exposure data (measured value) from the period of January 2010 to December 2015 were collected. The two major sources of information were literature found on the Web of knowledge ${ }^{\mathrm{TM}}$ database and China National Knowledge Infrastructure (CNKI) database. The China National Environmental Monitoring Centre (CNEMC) is another important source for environmental monitoring data. The CNEMC is the central center for measurement and control for routine environmental monitoring in China. Water quality measurements for the chemicals reviewed by CNEMC occurs on a monthly basis and follows the technical requirements for monitoring of surface water and waste water (HJ/T 912002). > 1600 of these PPCPS and EDCs data were detected in filtered water samples. For the remaining 200, whether the samples were filtered or not was not explained in the source literature; for $\mathrm{Zn}$ and $\mathrm{Hg}$, all data used in the study referred to the total concentrations (Su et al., 2017) (Table S3). Values of concentrations reported as 'non-detects' were assigned values of LOD $/ \sqrt{2}$ (Liu et al., 2016). The measurement data for $>60$ rivers and lakes were collected in the study area (Fig. 1). The summary of the data collected are shown in Table S3, and the environmental data in each river/lake is presented in Table S4.

\subsection{Toxicity information screening}

Toxicity references for the selected chemicals were guided by information provided by the ecotoxicology database (ECOTOX) on the USEPA website (https://cfpub.epa.gov/ecotox/). For each chemical, at least 4 species were required to estimate the toxicity (Aldenberg and Slob, 1993; Carriger et al., 2006), we took 8 species as a minimum requirement to avoid bias and reduce deviation. So the Web of knowledge $^{\mathrm{TM}}$ and CNKI database were also used to look for references on ecotoxicity to meet the requirements of quantity. To avoid the uncertainty of using non-native species toxic concentrations (Jin et al., 2015), species found in the Chinese aquatic environment were preferred, while laboratory standard test species were also considered (Table S5).

The aim was to include as wide a range of aquatic species and include both lethal and non-lethal effects. End-points used included lowest observed effect concentration (LOEC), the mid-point effect concentration $\left(\mathrm{EC}_{50}\right)$ and lethal concentration $\left(\mathrm{LC}_{50}\right)$. For one species only the lowest $\mathrm{EC}_{50}$ or $\mathrm{LC}_{50}$ would be entered in the final ecotoxicity database. If $\mathrm{EC}_{50}$ and $\mathrm{LC}_{50}$ values are unavailable, the $\mathrm{EC}_{\mathrm{xx}}, \mathrm{LC}_{\mathrm{xx}}$, $\mathrm{LOEC}$ were considered.

\subsection{Risk analysis}

Relative risk of the different PPCPs and EDCs compared the proximity of the median ecotoxicity concentration and median freshwater measured concentration (Formula (1)).

$R=M_{w} / M_{e}$

where $R$ is the relative risk, $M_{w}(\mu \mathrm{g} / \mathrm{L})$ is the median value of chemical concentrations in environmental fresh water and $M_{e}(\mu \mathrm{g} / \mathrm{L})$ is the median value of effect concentrations. Ranking of the dimensionless $R$ values represents ranking of chemicals' concern (Donnachie et al., 2014; Donnachie et al., 2016).

The ecotoxicity data could also be filtered to look at the relative risk for different species groups, such as only looking at fish or algae. Spatial distributions of PPCPs and EDCs studied were analyzed using the Arcmap module in ArcGIS V10.2 software (ESRI, Redland, CA, USA). The original data sources for population distribution and waste water discharge in the sub-regions were the statistical yearbooks from the China's National Bureau of Statistics.

\section{Results and discussion}

\subsection{Risk ranking based on toxicity for all freshwater species}

Risk ranking for the 12 PPCPs, EDCs and 2 metals based on comparison of the median ecotoxicity and measured values was shown in Fig. 2. The top 3 highest ranked organic compounds were LAS, NP and DEHP (Fig. 2). The relative risk of pharmaceuticals was at least 100 times lower than LAS. The pharmaceuticals of greatest concern from this group were antibiotics, NOR, SMZ and ERY. However, Zn posed a risk higher than all the organics while the risk posed by $\mathrm{Hg}$ was lower than LAS, NP and DEHP, but higher than all the pharmaceuticals. Although not used for risk ranking in this case, the results show some overlaps between the effect concentrations with measured Bohai Rim water concentrations for Zn, LAS, NP, DEHP, SMX and BPA (Fig. 2a), suggesting that some aquatic organisms were in danger.

This analysis indicates that the LAS is the highest risk from this group of organic contaminants for aquatic organisms of the Bohai Rim with a risk ratio of 0.0107 (Fig. 2b). In the freshwaters of the Bohai coastal region, the reported environmental concentrations for LAS ranged from 20 to $1220 \mu \mathrm{g} / \mathrm{L}$, with a median concentration of $35 \mu \mathrm{g} / \mathrm{L}$. The lowest (most sensitive) effect concentration was reported as $4 \mu \mathrm{g} / \mathrm{L}$, for a 6 days $\mathrm{LC}_{50}$ for adult Gammarus pulex (invertebrate), and for fish a level as low as $22 \mu \mathrm{g} / \mathrm{L}$ has been reported to be the 6 days $\mathrm{LC}_{50}$ for Cirrhinus mrigala (Lal et al., 1983). LAS is a very popular surfactant in both industrial and domestic detergents with a global production of 2.4 million tons/year in 1994, which accounts for $40 \%$ of all surfactants (Riu et al., 2001). It was reported that, in China the consumption was 


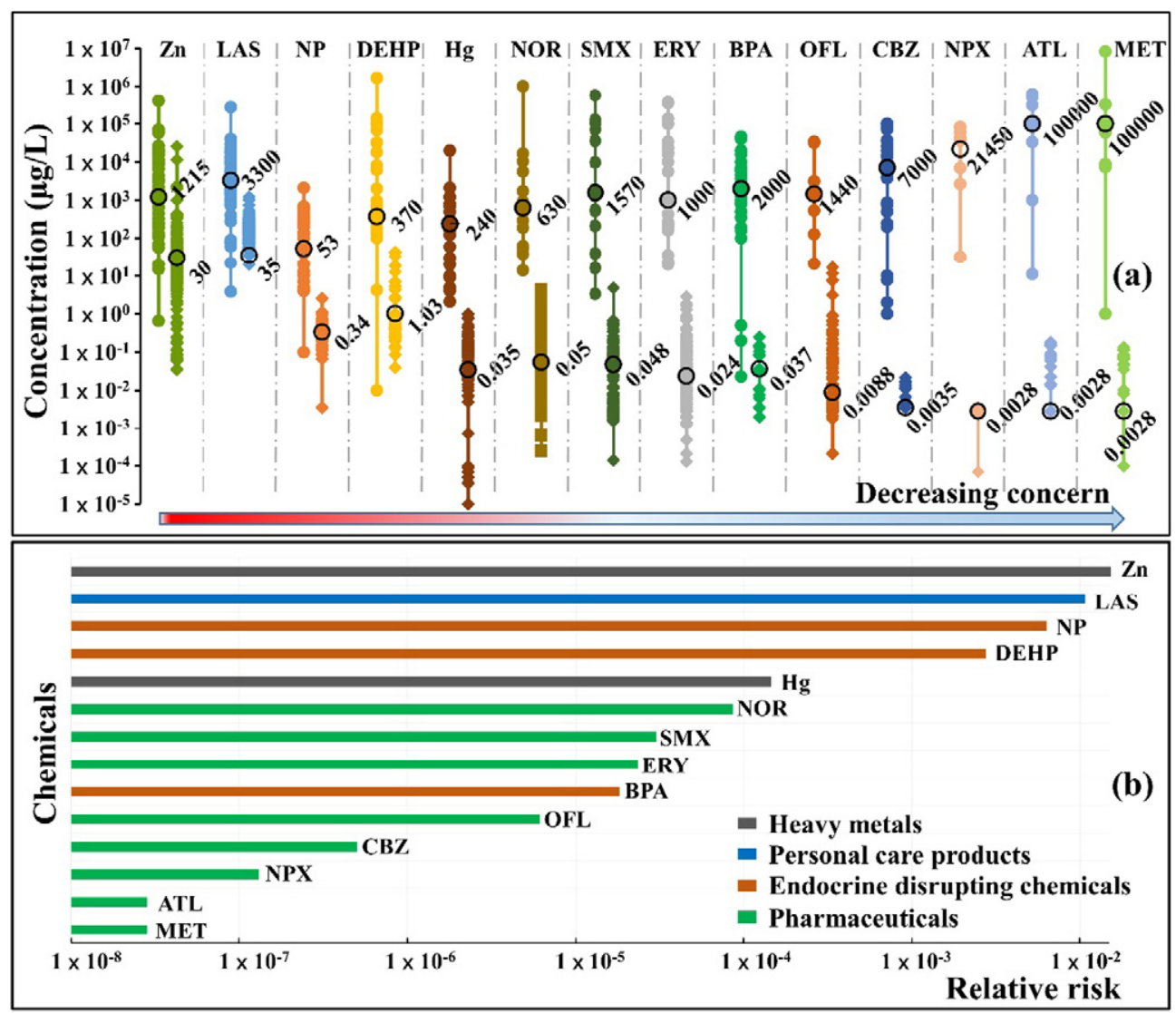

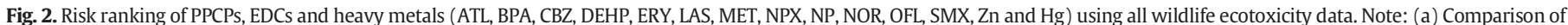

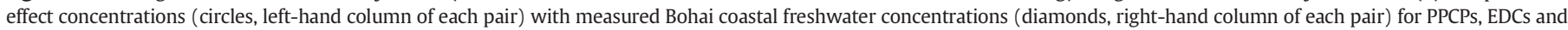

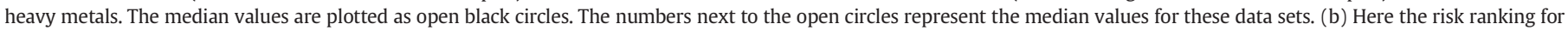
the chemicals is shown by plotting the ratios of the median environmental concentration and median effect concentration.

about $0.5-0.6$ million tons and the production was $>0.6$ million tons around 2010 (Fang et al., 2013).

The highest ranked pharmaceutical was the antibiotic NOR whose river measurements ranged from $0.00025 \mu \mathrm{g} / \mathrm{L}$ to $4.46 \mu \mathrm{g} / \mathrm{L}$, with a median of $0.054 \mu \mathrm{g} / \mathrm{L}$. Similar levels of NOR in environmental water was reported at Jianghan Plain (average value of $0.065 \mu \mathrm{g} / \mathrm{L}$ in surface water) by Yao et al. (2015), the Pearl River Estuary (median value of $0.067 \mu \mathrm{g} / \mathrm{L}$ in wet season) by Liang et al. (2013). The ecotoxicity values ranged from $14 \mu \mathrm{g} / \mathrm{L}$ to $100 \mathrm{mg} / \mathrm{L}$, with a median value of $630 \mu \mathrm{g} / \mathrm{L}$. The lowest reported effect level of $14 \mu \mathrm{g} / \mathrm{L}$ was the 1 day lowest effect concentration for sexually mature Carassius auratus (Goldfish) which caused increased superoxide dismutase production in the liver (Liu et al. 2014). Thus, the present study result revealed that the elevated levels of NOR were relatively safe for the aquatic organisms although we are not considering antibiotic resistance here. Fluoroquinolones (e.g. NOR and OFL), macrolides (e.g. ERY), and sulfonamides (e.g. SMX) are likely to be important based on the frequent and common usage of antibiotics in China, contributing approximately $15 \%, 20 \%$, and $12 \%$, respectively, to the total amount of antibiotics used for human and veterinary practices (Xu et al., 2009). In the present study, SMX and ERY ranked the first three pharmaceuticals with NOR.

A comparison of risk ranking results between in the Bohai Rim and in the UK using the similar methodology (Donnachie et al., 2016) was also conducted in this study. The phenomenon that metals posed a higher risk to aquatic organisms than pharmaceuticals is consistent with the findings in the UK. For both UK rivers and the Bohai Rim rivers the relative risk: $\mathrm{Zn}>\mathrm{Hg}$ was the same. However, the ranking of common pharmaceuticals was CBZ $>$ ATL $>$ NPX $>$ SMX $>$ MET in UK (Donnachie et al., 2016), while the order was SMX $>$ CBZ $>$ NPX $>$ ATL $=$ MET in China. China is the major producing and exporting country for sulfonamides
(Lun, 2005). The SMX exposure was 27 times higher in the Bohai Rim compared to that for UK rivers, and the effect median after filtering for native species is $1540 \mu \mathrm{g} / \mathrm{L}$ in China, much lower than that in UK $(31,350 \mu \mathrm{g} / \mathrm{L})$ (Donnachie et al., 2016). ATL had a higher relative risk for UK rivers than that in Bohai Rim. In Bohai coastal region ATL has a same rank with MET as a result of the same effect media concentration and the same water concentration. Although both the ATL and MET are beta-blockers used for cardiovascular diseases, ATL concentration in UK rivers was higher than MET, which reflects the possibility of the different prescribing habits or the different medication requirements in these two regions.

The metal Zn was ranked at a higher risk than all the other organics while Hg was lower but still posed a higher risk than all the pharmaceuticals. In the sequence of PPCPs and EDCs, surfactant (LAS) was ranked first risk chemical, two EDCs (NP and DEHP) were ranked the 2nd and 3rd. Antibiotics (NOR, SMX, ERY, OFL) were in the middle of the sequence, with NOR in the front. Endocrine disruptor BPA was ranked between them. Antibiotics were followed by antiepileptics (CBZ), antiinflammatory drugs (NPX), with $\beta$-blockers (ATL, MET) ranked in the last.

\subsection{Which wildife groups would be most at risk from PPCPs and EDCS?}

Risk ranking of the selected PPCPs and EDCs to the main organism groups, algae, fish and invertebrates was shown in Fig. 3. The first observation is that for the species groups of algae, fish and invertebrates each would rank LAS, NP and DEHP as their biggest threat (Fig. 3), despite the different orders. In other words, these particular surfactants/EDCs would impact on all main species groups. The major difference between the species groups is that BPA showed higher risk (rank 4) to fish and 


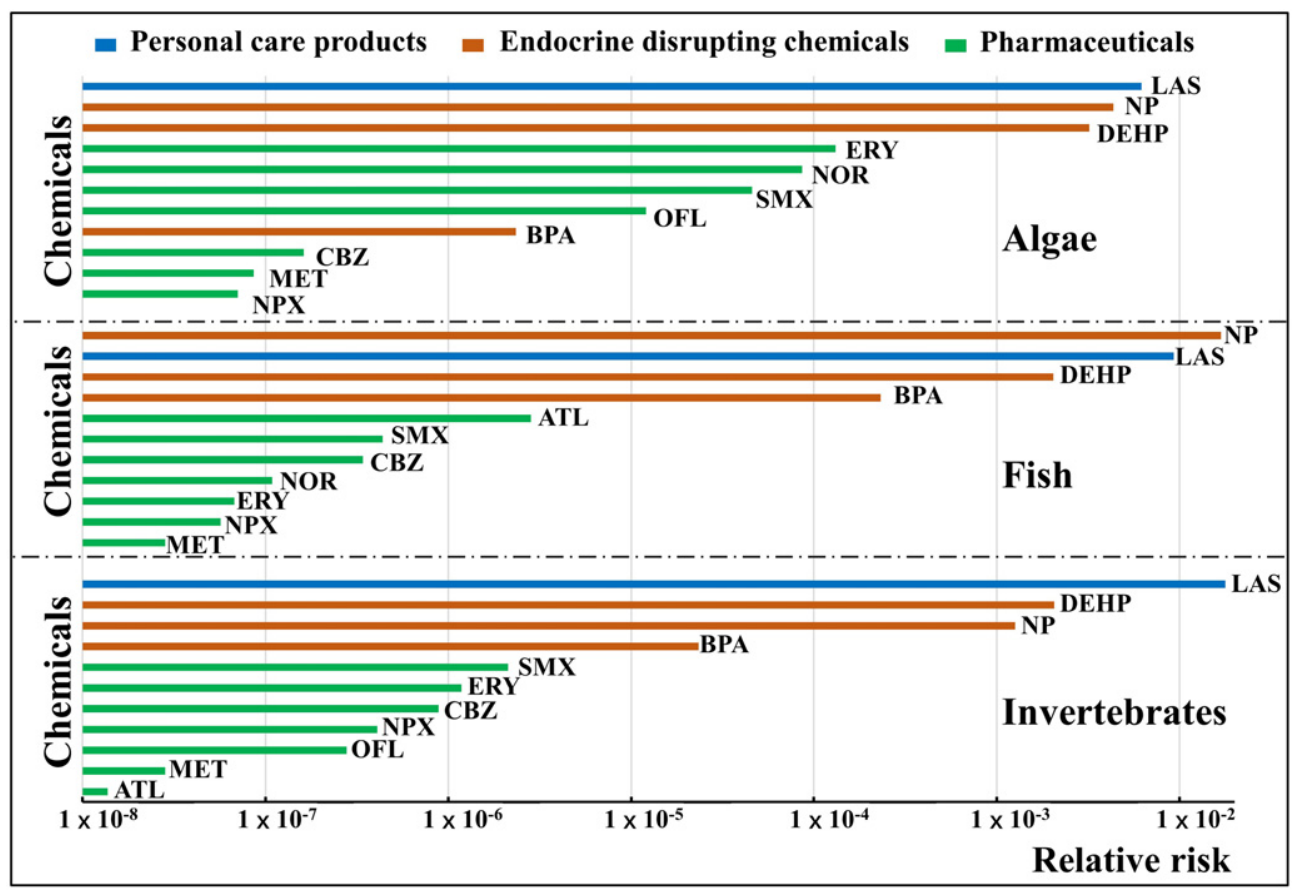

Fig. 3. Risk ranking of PPCPs and EDCs (ATL, BPA, CBZ, DEHP, ERY, LAS, MET, NPX, NP, NOR, OFL and SMX), by algae, fish and invertebrates.

invertebrates than all other pharmaceuticals, but it posed a less risk to algae (rank 8), in the queue of pharmaceuticals. Antibiotics were still ranked in the middle for algae (rank 4-7), but the rank of CBZ moved to the middle of the antibiotics for fish (7) and invertebrates (7). ERY posed high risk to algae (rank 4, top 1 in pharmaceuticals) but low risk to invertebrates (rank 6) and fish (rank 9). NOR showed high risk to algae (rank 5), but less risk to fish (rank 8). Anti-inflammatory drug NPX was at the last for algae and the next to last for fish, but was in the antibiotics sequence for invertebrates.

The risk difference to the organisms by a specific PPCP or EDC was mainly due to the sensitiveness of the organisms to the chemical. The pharmaceuticals were divided into 4 groups based on their function, including antibiotics, anti-inflammatory drugs, $\beta$-blockers and antiepileptics. With the studied chemicals in the category of surfactants and endocrine disruptors, 6 groups were obtained. The toxicity information for algae, fish and invertebrates was pooled together and the median explained the sensitiveness of the organism category (Fig. 4). This approach was aimed to identify the most sensitive species group to a specific chemical and to understand the change of sensitive species group in case of change in the chemical.

Surfactants (LAS) and one of the EDCs (DEHP) showed similar toxicity to the 3 categories respectively, the differences between the effect data for algae, fish and invertebrates were less than one order of magnitude on median, so the similar effect to all these species. Fish was more sensitive organism to the NP and BPA than algae and invertebrates, thus NP and BPA pose greater risk to fish other than algae and invertebrates which may represent their typical EDCs character.

An obvious difference showed between the species groups was that algae were the most sensitive organisms to the toxicity of antibiotics, while fish was the least sensitive and have least risk posed by antibiotics due to the highest median toxic value. Antiepileptics (CBZ) posed similar risk to the 3 categories, however, it is suggested that further research

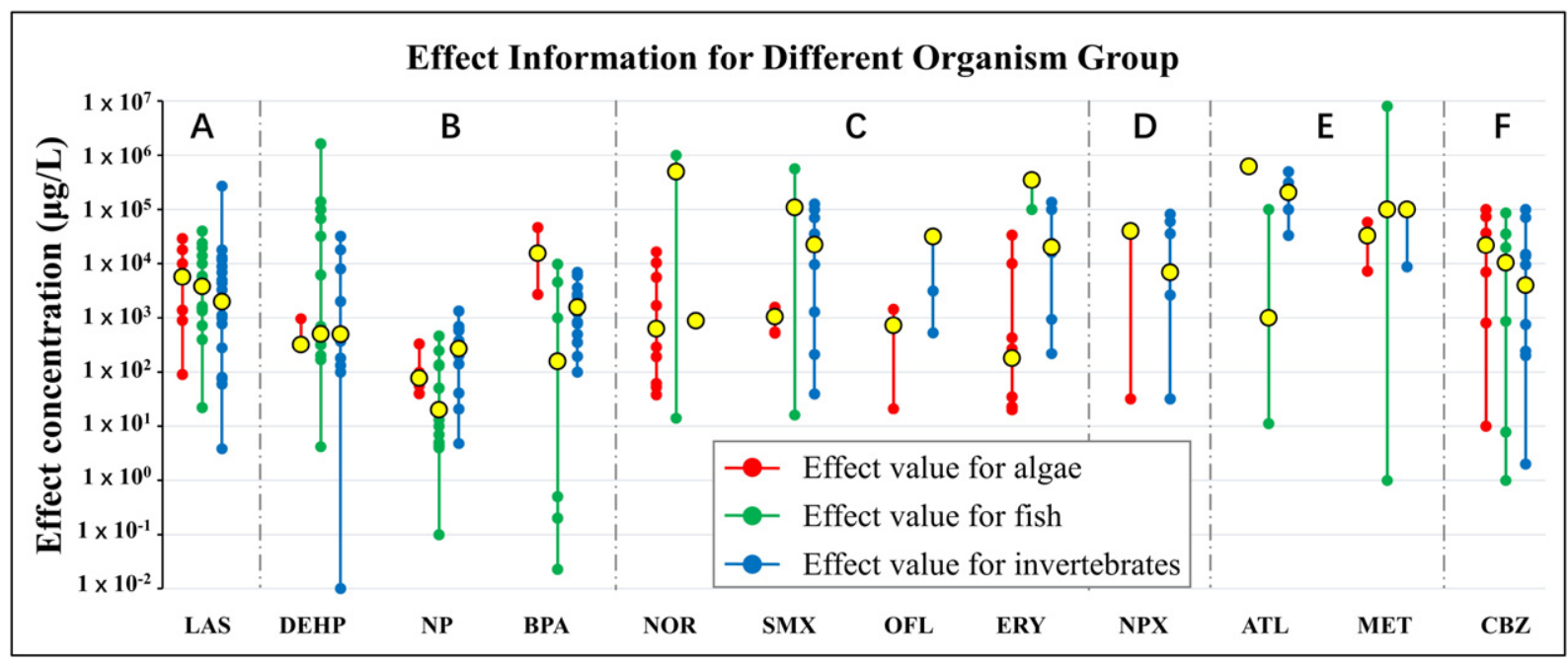

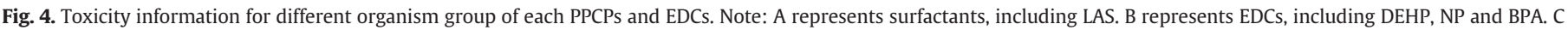

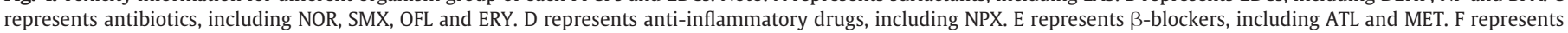
antiepileptics, including CBZ. The median values are plotted as yellow circles with black border. 
is needed with more chemicals due to the limited data availability (only 1 chemical). It must be admitted that the species ecotoxicity information is not equally spread between these chemicals (Fig. 4). This is particularly true for the pharmaceuticals since relatively few ecotoxicity reports are available for some of these chemicals.

\subsection{Spatial and temporal distribution of PPCPs and EDCs risk}

The maximum relative risk value of each PPCPs and EDCs were studied to identify the hotspots of risks in Bohai Rim. In addition, LAS was selected as a representative chemical to analyze the spatial and temporal risk distribution in the whole Bohai Rim since it posed the greatest risk to all the organisms and it was routinely monitored in China. The Liaohe River basin was selected as a case study area for the character analysis of chemicals risk along the rivers due to its abundant available exposure data. LAS and ERY were selected as representative personal care product and pharmaceuticals respectively.

\subsubsection{Hotspots of PPCPS and EDCs risks in Bohai Rim}

The highest surfactant LAS risk was located in Ziya New River in Hebei province (Fig. 5a), with the relative risk of 0.37 (Fig. 5b). The south sewage canal in Tianjin showed a high risk associated with NP (Fig. 5a), with the relative risk of 0.05 (Fig. 5b). This may be due to the discharge of industrial as well as municipal sewage in these rivers hence it causes high risk from both production and consumption processes.

Hotspots for DEHP and BPA were located in Liaohe River basin (Fig. 5a). The Haicheng River showed a high relative risk for DEHP $(0.12$, Fig. 5b), which may be linked with the number of printing and dyeing industries that are located in Haicheng county (Zhang et al., 2015). The greatest concentration for BPA with a relative risk of $1.2 \times 10^{-4}$ was observed in Daliao River estuary, in which urban industrial and municipal sewage is discharged from the Yingkou region (Liu, 2012).

Concerning the pharmaceuticals, the Qing River and Tonghui River, (situated in densely populated urban area of Beijing, Fig. S1), had the highest recorded concentrations and hence risks including NOR 0.007, OFL 11.77 , NPX $1.67 \times 10^{-7}$, CBZ $3.04 \times 10^{-6}$, ATL $1.81 \times 10^{-6}$ and MET $1.34 \times 10^{-6}$. These levels were most likely linked to discharge from the large human population and the Qing River and Gaobeidian waste water treatment plants (WWTPs) (Wang et al., 2015). The ERY risk hotspot was located in Xinmin sewage ditch in Xinmin urban region and SMX hotspot was located in Wangyang River in Shijiazhuang, both rivers were receiving water bodies for urban sewage (Bai et al., 2014; Jiang et al., 2014).

The results suggest the importance of the industrial component to hotspots for surfactants (LAS) and EDCs (DEHP, NP and BPA). The high consumption in urban regions where medical care was prevalent and population was dense was the predominant reason for pharmaceuticals. All these phenomena highlight the effect of anthropogenic activities on exposure to pharmaceuticals in the aquatic environment.

\subsubsection{Spatial and temporal distribution of LAS in Bohai Rim}

Fortunately, a very comprehensive dataset is available for LAS for the rivers of this region thanks to it being routinely monitored by the CNEMC (65 water quality monitoring sites with monthly data for 2013 was available). Given that it is the highest risk ranked chemical of the pharmaceuticals, personal care products and endocrine disrupting chemicals it is helpful to look at it in more detail.

As shown in Fig. 6a, those sites with the relatively high risk (as relative risk $>0.04$ ), were mainly located in the area around Beijing and Tianjin city in the northern Haihe River Basin. Two sites with highest risk were located in lower Ziya New River in Cangzhou City, Hebei

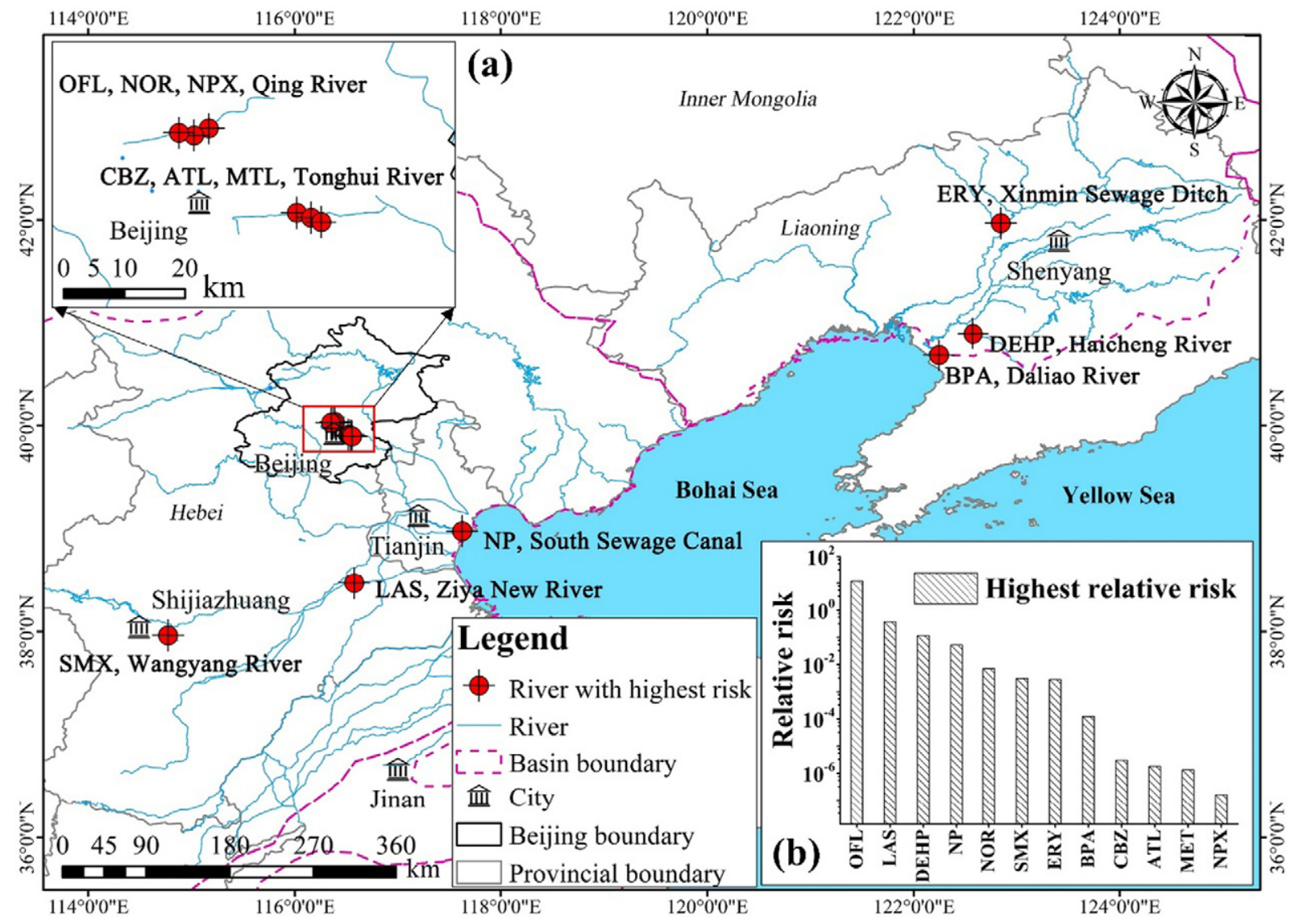

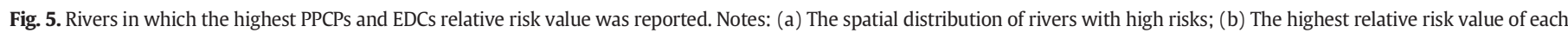
chemicals shown by histogram. 
Province and North Canal in Beijing City, with the relative risks of 0.14 and 0.13 respectively. The Ziya River system and North Canal system are two important sub-basins of the Haihe River basin system. Large amounts of untreated domestic sewage and industrial wastewater are discharged into the Ziya River system and finally go into Ziya New River which flows into the Bohai Sea. The discharge of untreated wastewater from industrial units in the Ziya New River system has been noted in local news media, so these higher risk values may confirm the poor treatment in this area. Similarly, the other hotspot area at the Beijing section of North Canal system is an industry-intensive area with high population density of 3500 people per square kilometer (Jing et al., 2013). It is reported to be a low sewage treatment capacity and imperfect wastewater network in this area (Jing et al., 2013). LAS risk is proving to be a good marker of poor industrial and municipal wastewater treatment in this area.

The LAS concentration and relative risk were at a median level in January, and then reached a peak in March, with the minimum value in August (Fig. 6b). In China the wet season is May-October, and highest risks were associated with the dry season i.e. November-February. Similar changes of LAS and PPCPs between seasons were also reported in previous studies in different areas (Inaba and Amano, 1988; Shimizu et al., 2013; Xu et al., 2013; Tong et al., 2014). Apart from dilution playing a major role, warmer water temperatures exist in the wet season would encourage the LAS biodegradation, both in the WWTPs and rivers. LAS biodegradation is regarded as the major pathway of LAS elimination from the water body (Berna et al., 1991; Takada and Ogura, 1992). However, the biodegradation process was affected by temperature (Mungray and Kumar, 2009; Wang et al., 2010), longer acclimation periods were needed by the microorganisms at lower temperature $\left(9^{\circ} \mathrm{C}\right.$ ) in WWTPs (Prats et al., 2006). Therefore, it was possible to have a deterioration of elimination efficiency of LAS in WWTPs using biological approaches in Bohai coastal region with an air temperature below freezing in winter. There was another factor which may result in more LAS in the river in rainy season. The combined sewer system, which may still exist in some areas, may cause some wastewater discharged directly into the rivers and make shock loadings to the WWTPs in rainy season. However, the fact that lower river concentration of LAS in wet season indicated the influence of the above factor might be limited.

\subsubsection{Spatial distribution of LAS and ERY risks in Liaohe River basin}

The relative risk reflects that the risks posed by LAS to aquatic organisms in rivers of Liaohe River basin were between 0.016-0.043 (Fig. 6a). Three sites with high risk were located in the upper Hun River (LN1), the lower Taizi River (LN17) and Xixihe River (LN16) and the relative risk was observed as $0.043,0.041$ and 0.04 , respectively. Along the river, the LAS relative risk was observed as 0.021 at LN2 in Hun River after the Suzi River, 0.022 at LN9 in Daliao River and 0.017 at LN15 in Daling River, respectively. This may be due to the dilution effects from flow volume increased by the river confluence.

In the main streams of Daling River, Liao River and Hun river, the risk in general was higher in the upstream, and decreased with the flow and was lower in middle and downstream. Besides the dilution effects, biodegradation of LAS by microorganisms and adsorption of LAS by suspended particles or sediments are probably the other reasons for lower risk (González-Mazo et al., 1997; Wang et al., 2010). Also, the half-lives reported for LAS were no longer than 2 days in river in the presence of sediments (Larson and Payne, 1981; Larson et al., 1993; Fox et al., 2000).

ERY is one among the commonly used antibiotic and frequently detected macrolide in natural water (Kim and Carlson, 2007; Xu et al., 2013; Xue et al., 2013; Chen et al., 2015). For the present study, ERY

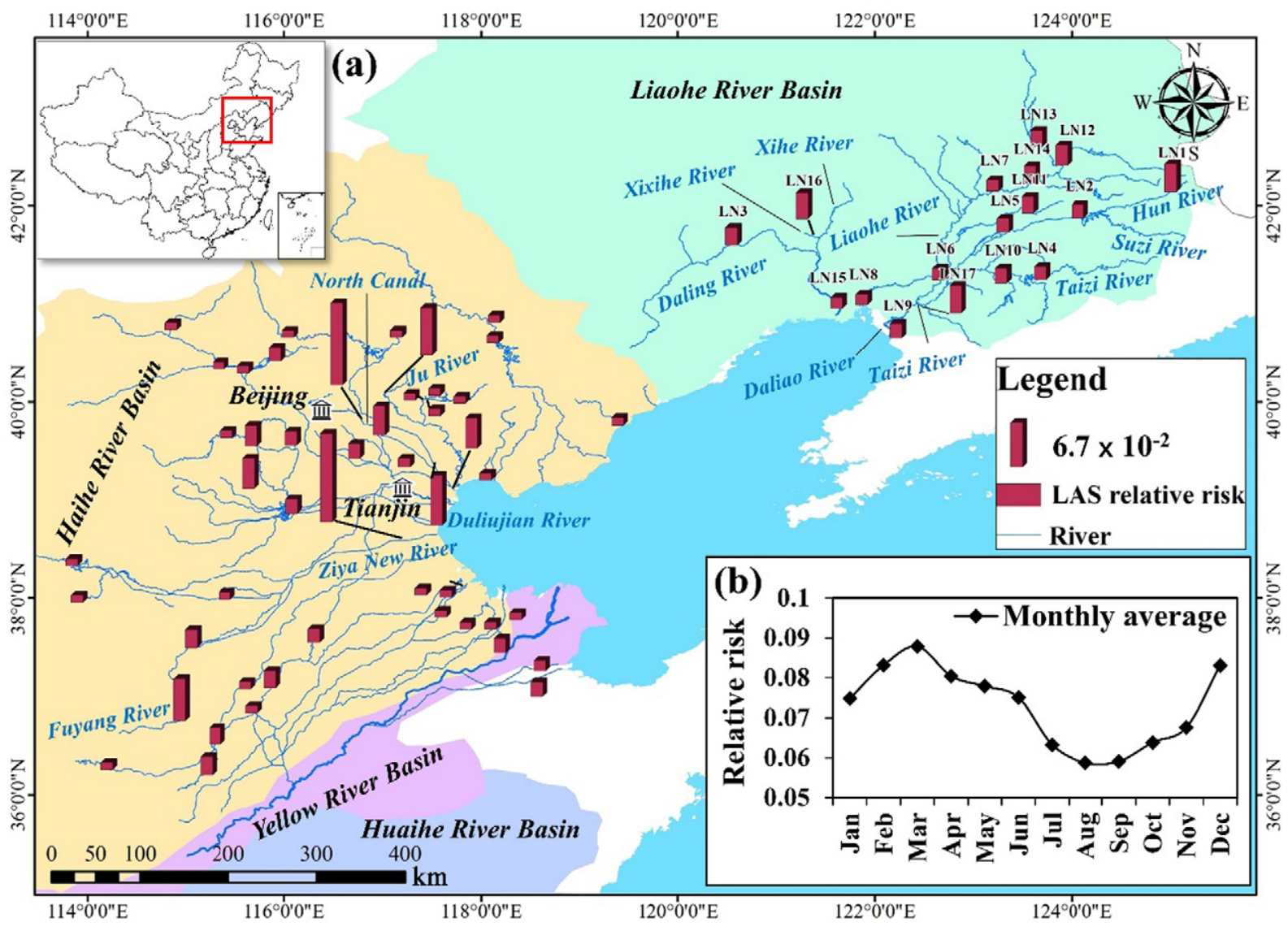

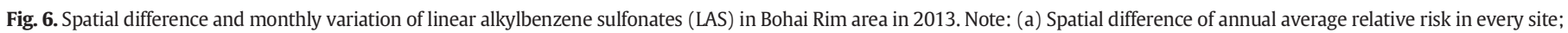
(b) monthly variation of space average relative risk. 
risk in Liaohe River region was selected as a case of representative pharmaceuticals risk distribution since ERY posed high risk to aquatic organisms (ranked 3 in the pharmaceuticals) and the risk hotspot was located at Liaohe river region. The spatial distribution of ERY risk calculated from the measurements at 50 sampling sites in Liaohe River Basin (Bai et al., 2014) was shown in Fig. 7.

The relative risk of ERY to aquatic organisms in rivers of Liaohe River basin were ranged between $2.45 \times 10^{-6}-0.002$ (Fig. 7). The sites with high ERY risk were in the tributaries of Liaohe river (Xinmin sewage ditch, L17) and Taizi River (Sha river, T44), and the relative risk was 0.002 and 0.001 respectively. The Xinmin sewage ditch was linked to urban area and Sha river might be influenced by the Anshan First WWTP effluent (Bai et al., 2014). While the risk became dramatically lower at downstream positions, L18 in Liaohe River and T45 in Taizi River. It was similar to LAS due to the dilution effect from the confluence of main streams and tributaries.

ERY risk was higher in main stream of Hun river than in Liaohe and Taizi rivers. In the main streams of all the 3 main rivers, on the contrary to LAS, the ERY risk was increased with the flow, and was higher in middle and downstream. This is most probably linked to the differences of persistence between the two molecules with ERY being very much more persistent than LAS. ERY was reported to be stable in fresh water because it is a broad spectrum antibiotic which can only be degraded by some specific bacteria that is resistant to it. In addition, photo-degradation under natural condition is inefficient and slow (Batchu et al., 2014). Although the sediment can be a major sink for antibiotics in the aquatic ecosystem through sorption to solid surfaces (Kim and Carlson, 2007), this process may take a long time (Wu et al., 2015). Moreover, it is unclear whether elimination by sorption is an irreversible process (Kummerer, 2004). According to the microcosm study conducted by Wu et al. (2015), the half-life for ERY in aquatic ecosystem with sediment was 42 days. It can be even longer in different conditions ( $\geq 1$ year) (Zuccato et al., 2005). This fairly long half-life of ERY will contribute to its persistence in natural water bodies.

\section{Conclusions}

River monitoring for many emerging chemicals such as pharmaceuticals is still rather limited in China. Similarly, the ecotoxicity dataset is not as extensive as we would like. Nevertheless, it is still worthwhile to risk rank the chemical contaminants in major Chinese rivers based on what we know now. Risk ranking of this group of PPCPs and EDCs based on a comparison of the median ecotoxicity and river concentrations has not put pharmaceuticals as the group of highest concern.

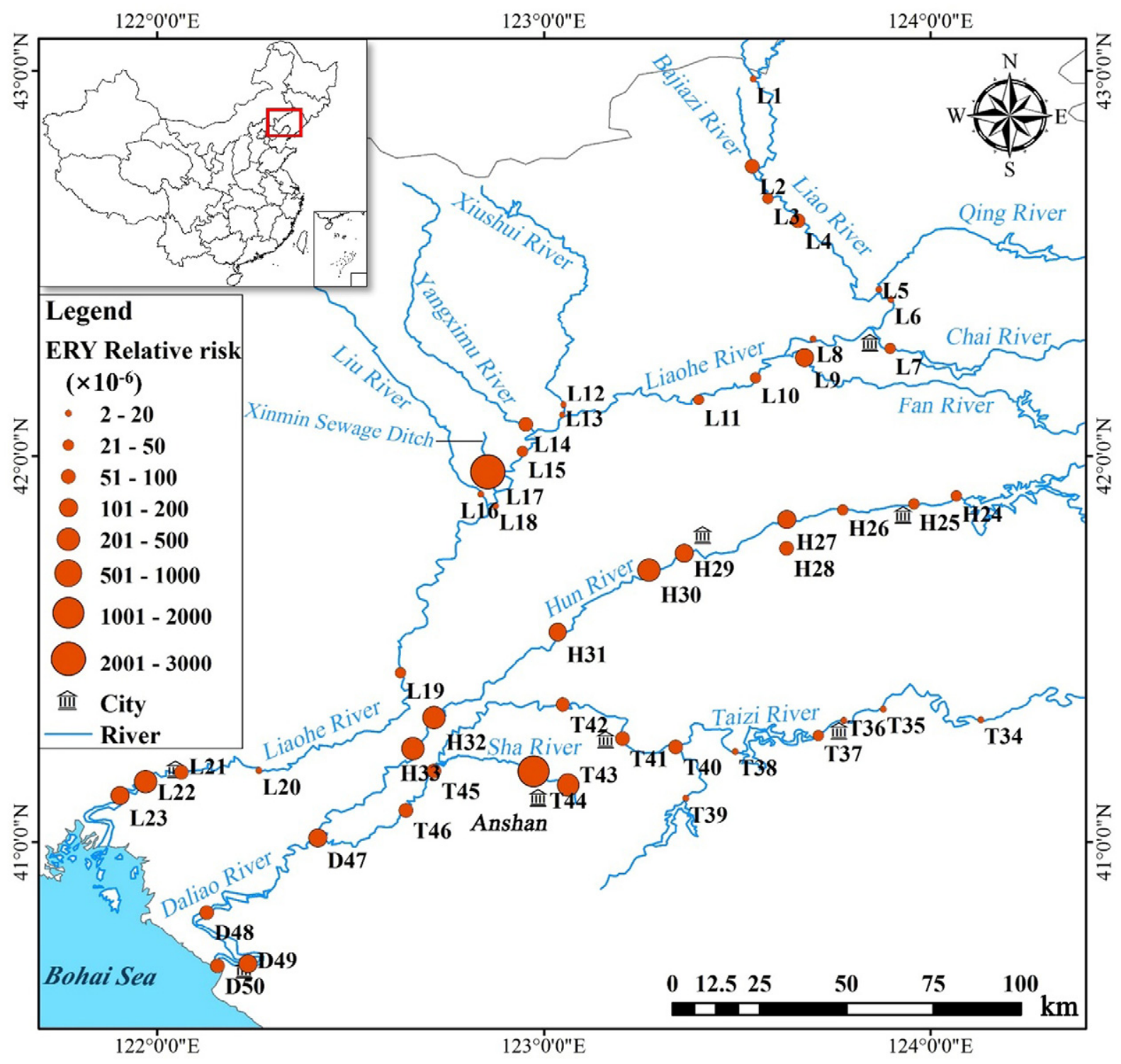

Fig. 7. Spatial distribution of erythromycin (ERY) relative risk in Liaohe River Basin in 2012. 
Instead, the surfactant LAS and surfactant break-down product NP are the chemicals of greatest concern, their relative risks were higher even than metal Hg. LAS had the most measured data where levels would exceed known effect levels. This would be most likely to occur in the December to March period around Beijing and Tianjin city on the northern Haihe River Basin. LAS and DEHP would affect equally algae, fish and invertebrate groups. The highest risk ranked pharmaceuticals were the antibiotics norfloxacin, sulfamethoxazole and erythromycin (ERY) and they showed higher risk to algae, invertebrates and the least risk to fish. Municipal sewage effluent linked to urban areas was considered to be the major source of pharmaceuticals. Take the widespread used surfactant LAS with relatively high risk and widely abused antibiotic ERY for example, the dilution effects were the common feature of LAS and ERY risk and the difference of LAS and ERY risk pattern along the rivers was mainly affected by the elimination process. Therefore, different measures should be taken. It is necessary to continue with this riskranking and temporal and spatial variation exploring exercise in other areas of China. And also it is recommended that the systematic research is needed to focus the efforts on removing chemicals with hazardous effects and replace them with more eco-friendly chemicals.

\section{Acknowledgements}

This study was supported by the National Natural Science Foundation of China under Grant No. 41420104004, No. 41371488, No. 41271487, No. 41671483 and No. 21307165, the Key Project of the Chinese Academy of Sciences under Grant No. KZZD-EW-TZ-12, and the National Fundamental Field Study Program (No. 2013FY11110). The UK authors are grateful for support from Newton fund provided by NERC. We would like to thank the editors and reviewers for their valuable comments and suggestions.

\section{Appendix A. Supplementary data}

Supplementary data to this article can be found online at http://dx. doi.org/10.1016/j.scitotenv.2017.03.011.

\section{References}

Aldenberg, T., Slob, W., 1993. Confidence limits for hazardous concentrations based on logistically distributed NOEC toxicity data. Ecotoxicol. Environ. Saf. 25 (1), 48-63.

Bai, Y., Meng, W., Xu, J., Zhang, Y., Guo, C., 2014. Occurrence, distribution and bioaccumulation of antibiotics in the Liao River Basin in China. Environ. Sci. Process. Impacts 16 (3), 586-593.

Batchu, S.R., Panditi, V.R., O'Shea, K.E., Gardinali, P.R., 2014. Photodegradation of antibiotics under simulated solar radiation: implications for their environmental fate. Sci. Total Environ. 470-471, 299-310.

Bendz, D., Paxeus, N.A., Ginn, T.R., Loge, F.J., 2005. Occurrence and fate of pharmaceutically active compounds in the environment, a case study: Hoje River in Sweden. J. Hazard. Mater. 122 (3), 195-204.

Berna, J.L., Moreno, A., Ferrer, J., 1991. The behaviour of LAS in the environment. J. Chem. Technol. Biotechnol. 50 (3), 387-398.

Boxall, A.B., Rudd, M.A., Brooks, B.W., Caldwell, D.J., Choi, K., Hickmann, S., Innes, E., Ostapyk, K., Staveley, J.P., Verslycke, T., Ankley, G.T., Beazley, K.F., Belanger, S.E., Berninger, J.P., Carriquiriborde, P., Coors, A., Deleo, P.C., Dyer, S.D., Ericson, J.F. Gagne, F., Giesy, J.P., Gouin, T., Hallstrom, L., Karlsson, M.V., Larsson, D.G., Lazorchak J.M., Mastrocco, F., McLaughlin, A., McMaster, M.E., Meyerhoff, R.D., Moore, R. Parrott, J.L., Snape, J.R., Murray-Smith, R., Servos, M.R., Sibley, P.K., Straub, J.O. Szabo, N.D., Topp, E., Tetreault, G.R., Trudeau, V.L., Van Der Kraak, G., 2012. Pharmaceuticals and personal care products in the environment: what are the big questions? Environ. Health Perspect. 120 (9), 1221-1229.

Boyd, G.R., Reemtsma, H., Grimm, D.A., Mitra, S., 2003. Pharmaceuticals and personal care products (PPCPs) in surface and treated waters of Louisiana, USA and Ontario, Canada. Sci. Total Environ. 311 (1-3), 135-149.

Bu, Q.W., Wang, B., Huang, J., Deng, S.B., Yu, G., 2013. Pharmaceuticals and personal care products in the aquatic environment in China: a review. J. Hazard. Mater. 262, 189-211.

Carriger, J.F., Rand, G.M., Gardinali, P.R., Perry, W.B., Tompkins, M.S., Fernandez, A.M., 2006. Pesticides of potential ecological concern in sediment from south Florida canals: an ecological risk prioritization for aquatic arthropods. Soil Sediment Contam. 15 (1), 21-45.

Chen, H., Liu, S., Xu, X.-R., Zhou, G.-J., Liu, S.-S., Yue, W.-Z., Sun, K.-F., Ying, G.-G., 2015. Antibiotics in the coastal environment of the Hailing Bay region, South China Sea: spatia distribution, source analysis and ecological risks. Mar. Pollut. Bull. 95 (1), 365-373.
Daughton, C.G., Ternes, T.A., 1999. Pharmaceuticals and personal care products in the environment: agents of subtle change? Environ. Health Perspect. 107, 907-938.

De Garcia, S.A.O., Pinto, G.P., Garcia-Encina, P.A., Irusta-Mata, R., 2014. Ecotoxicity and environmental risk assessment of pharmaceuticals and personal care products in aquatic environments and wastewater treatment plants. Ecotoxicology 23 (8), 1517-1533.

Delgado, M., Bigeriego, M., Guardiola, E., 1993. Uptake of Zn, Cr and Cd by water hyacinths. Water Res. 27 (2), 269-272.

Donnachie, R.L., Johnson, A.C., Moeckel, C., Pereira, M.G., Sumpter, J.P., 2014. Using riskranking of metals to identify which poses the greatest threat to freshwater organisms in the UK. Environ. Pollut. 194, 17-23.

Donnachie, R.L., Johnson, A.C., Sumpter, J.P., 2016. A rational approach to selecting and ranking some pharmaceuticals of concern for the aquatic environment and their relative importance compared to other chemicals. Environ. Toxicol. Chem. 35 (4), 1021-1027.

Fang, Y.J., Kong, L.N., Zhou, D.P., Zhang, Y.Y., 2013. Research and development of surfactants for daily use. China Cleaning Ind. (02), 41-48 (In Chinese).

Fox, K., Holt, M., Daniel, M., Buckland, H., Guymer, I., 2000. Removal of linear alkylbenzene sulfonate from a small Yorkshire stream: contribution to GREAT-ER project\# 7. Sci. Total Environ. 251, 265-275.

Gaw, S., Thomas, K.V., Hutchinson, T.H., 2014. Sources, impacts and trends of pharmaceuticals in the marine and coastal environment. Philos. Trans. R. Soc. B 369 (1656), 20130572.

González-Mazo, E., Honing, M., Barceló, D., Gómez-Parra, A., 1997. Monitoring long-chain intermediate products from the degradation of linear alkylbenzene sulfonates in the marine environment by solid-phase extraction followed by liquid chromatography/ ion spray mass spectrometry. Environ. Sci. Technol. 31 (2), 504-510.

Guillette, L.J., Crain, D.A., Rooney, A.A., Pickford, D.B., 1995. Organization versusactivation the role of endocrine-disrupting contaminants (EDCS) during embryonic-development in wildlife. Environ. Health Perspect. 103, 157-164.

Guo, L., Wang, D., Qiu, J., Wang, L., Liu, Y., 2009. Spatio-temporal patterns of land use change along the Bohai Rim in China during 1985-2005. J. Geogr. Sci. 19 (5), 568-576.

Hernando, M.D., Mezcua, M., Fernandez-Alba, A.R., Barcelo, D., 2006. Environmental risk assessment of pharmaceutical residues in wastewater effluents, surface waters and sediments. Talanta 69 (2), 334-342.

Inaba, K., Amano, K., 1988. HPLC determination of linear alkylbenzenesulfonate (LAS) in aquatic environment - seasonal-changes in LAS concentration in polluted lake water and sediment. Int. J. Environ. Anal. Chem. 34 (3), 203-213.

Jiang, W.W., Yan, Y., Ma, M., Wang, D.H., Luo, Q., Wang, Z.J., Satyanarayanan, S.K., 2012. Assessment of source water contamination by estrogenic disrupting compounds in China. J. Environ. Sci. 24 (2), 320-328.

Jiang, Y.H., Li, M.X., Guo, C.S., An, D., Xu, J., Zhang, Y., Xi, B.D., 2014. Distribution and ecological risk of antibiotics in a typical effluent-receiving river (Wangyang River) in north China. Chemosphere 112, 267-274.

Jin, X., Wang, Z., Wang, Y., Lv, Y., Rao, K., Jin, W., Giesy, J.P., Leung, K.M., 2015. Do water quality criteria based on nonnative species provide appropriate protection for native species? Environ. Toxicol. Chem. 34 (8), 1793-1798.

Jing, H., Zhang, Z., Guo, J., 2013. Water pollution characteristics and pollution sources of Bei Canal river system in Beijing. China Environ. Sci. 33 (2), 319-327.

Kasprzyk-Hordern, B., Dinsdale, R.M., Guwy, A.J., 2008. The occurrence of pharmaceuticals, personal care products, endocrine disruptors and illicit drugs in surface water in South Wales, UK. Water Res. 42 (13), 3498-3518.

Kim, S.-C., Carlson, K., 2007. Temporal and spatial trends in the occurrence of human and veterinary antibiotics in aqueous and river sediment matrices. Environ. Sci. Technol. 41 (1), 50-57.

Kolpin, D.W., Furlong, E.T., Meyer, M.T., Thurman, E.M., Zaugg, S.D., Barber, L.B., Buxton, H.T. 2002. Pharmaceuticals, hormones, and other organic wastewater contaminants in US streams, 1999-2000: a national reconnaissance. Environ. Sci. Technol. 36 (6), $1202-1211$

Kummerer, K., 2004. Resistance in the environment. J. Antimicrob. Chemother. 54 (2), 311-320.

Lal, H., Misra, V., Viswanathan, P., Murti, C.K., 1983. Comparative studies on ecotoxicology of synthetic detergents. Ecotoxicol. Environ. Saf. 7 (6), 538-545.

Larson, R., Payne, A., 1981. Fate of the benzene ring of linear alkylbenzene sulfonate in natural waters. Appl. Environ. Microbiol. 41 (3), 621-627.

Larson, R., Rothgeb, T., Shimp, R., Ward, T., Ventullo, R., 1993. Kinetics and practical significance of biodegradation of linear alkylbenzene sulfonate in the environment. J. Am. Oil Chem. Soc. 70 (7), 645-657.

Li, J., Li, F., Liu, Q., Zhang, Y., 2014. Trace metal in surface water and groundwater and its transfer in a Yellow River alluvial fan: evidence from isotopes and hydrochemistry. Sci. Total Environ. 472, 979-988.

Liang, X., Chen, B., Nie, X., Shi, Z., Huang, X., Li, X., 2013. The distribution and partitioning of common antibiotics in water and sediment of the Pearl River Estuary, South China. Chemosphere 92 (11), 1410-1416.

Liu, C., 2012. Distribution Characteristics and Ecological Risk Assessment of Typical Phenolic Endocrine Disrupting Chemicals in Daliao River Estuary. Ocean University of China (In Chinese).

Liu, J.-L., Wong, M.-H., 2013. Pharmaceuticals and personal care products (PPCPs): a review on environmental contamination in China. Environ. Int. 59, 208-224.

Liu, J., Lu, G., Wu, D., Yan, Z., 2014. A multi-biomarker assessment of single and combined effects of norfloxacin and sulfamethoxazole on male goldfish (Carassius auratus). Ecotoxicol. Environ. Saf. 102, 12-17.

Liu, Z., Lu, Y., Wang, T., Wang, P., Li, Q., Johnson, A.C., Sarvajayakesavalu, S., Sweetman, A.J., 2016. Risk assessment and source identification of perfluoroalkyl acids in surface and ground water: spatial distribution around a mega-fluorochemical industrial park, China. Environ. Int. 91, 69-77. 
Liu, J., Chen, B., Jefferson, T.A., Wang, H., Yang, G., 2017. Trace element concentrations, risks and their correlation with metallothionein genes polymorphism: a case study of narrow-ridged finless porpoises (Neophocaena asiaeorientalis) in the East China Sea. Sci. Total Environ. 575, 628-638.

Lun, Z., 2005. The current situation in production, marketing and tendency of sulfonamides. China Pharm. 8, 004.

Mungray, A.K., Kumar, P., 2009. Fate of linear alkylbenzene sulfonates in the environment: a review. Int. Biodeterior. Biodegrad. 63 (8), 981-987.

Petrovic, M., Hernando, M.D., Diaz-Cruz, M.S., Barcelo, D., 2005. Liquid chromatographytandem mass spectrometry for the analysis of pharmaceutical residues in environmental samples: a review. J. Chromatogr. A 1067 (1-2), 1-14.

Prats, D., López, C., Vallejo, D., Varó, P., Leon, V.M., 2006. Effect of temperature on the biodegradation of linear alkylbenzene sulfonate and alcohol ethoxylate. J. Surfactant Deterg. 9 (1), 69-75.

Riu, J., Martinez, E., Barcelo, D., Ginebreda, A., Tirapu, L.L., 2001. LC-MS determination of linear alkylbenzene sulfonates and their carboxylic degradation products in influent and effluent water samples and sludges from sewage-treatment plants. Fresenius J. Anal. Chem. 371 (4), 448-455.

Rosi-Marshall, E.J., Royer, T.V., 2012. Pharmaceutical compounds and ecosystem function: an emerging research challenge for aquatic ecologists. Ecosystems 15 (6), 867-880.

Santos, L., Araujo, A.N., Fachini, A., Pena, A., Delerue-Matos, C., Montenegro, M., 2010. Ecotoxicological aspects related to the presence of pharmaceuticals in the aquatic environment. J. Hazard. Mater. 175 (1-3), 45-95.

Shimizu, A., Takada, H., Koike, T., Takeshita, A., Saha, M., Rinawati, Nakada, N., Murata, A., Suzuki, T., Suzuki, S., Chiem, N.H., Tuyen, B.C., Viet, P.H., Siringan, M.A., Kwan, C. Zakaria, M.P., Reungsang, A., 2013. Ubiquitous occurrence of sulfonamides in tropical Asian waters. Sci. Total Environ. 452-453, 108-115.

Su, C., Lu, Y., Johnson, A.C., Shi, Y., Zhang, M., Zhang, Y., Juergens, M.D., Jin, X., 2017. Which metal represents the greatest risk to freshwater ecosystem in Bohai Region of China? Ecosyst. Health Sustain. 3 (2).

Takada, H., Ogura, N., 1992. Removal of linear alkylbenzenesulfonates (LAS) in the Tamagawa Estuary. Mar. Chem. 37 (3), 257-273.

Tong, L., Huang, S.B., Wang, Y.X., Liu, H., Li, M.J., 2014. Occurrence of antibiotics in the aquatic environment of Jianghan Plain, central China. Sci. Total Environ. 497 180-187.

Wang, J., Da, L., Song, K., Li, B.L., 2008. Temporal variations of surface water quality in urban, suburban and rural areas during rapid urbanization in Shanghai, China. Environ. Pollut. 152 (2), 387-393.
Wang, Z., Xiao, B.D., Wu, X.Q., Tu, X.H., Wang, Y.C., Sun, X.L., Song, L.R., 2010. Linear alkylbenzene sulfonate (LAS) in water of Lake Dianchi-spatial and seasonal variation, and kinetics of biodegradation. Environ. Monit. Assess. 171 (1-4), 501-512.

Wang, T., Khim, J.S., Chen, C., Naile, J.E., Lu, Y., Kannan, K., Park, J., Luo, W., Jiao, W., Hu, W. Giesy, J.P., 2012. Perfluorinated compounds in surface waters from Northern China: comparison to level of industrialization. Environ. Int. 42, 37-46.

Wang, Z., Zhang, X.H., Huang, Y., Wang, H., 2015. Comprehensive evaluation of pharmaceuticals and personal care products (PPCPs) in typical highly urbanized regions across China. Environ. Pollut. 204, 223-232.

Wu, Y., Yang, C., Tang, T., Guo, X., Dang, Z., 2015. Distribution of erythromycin in aquatic ecosystem: microcosm study. Acta Sci. Circumst. 35 (03), 897-902 (In Chinese).

Xu, W.H., Zhang, G., Zou, S.C., Ling, Z.H., Wang, G.L., Yan, W., 2009. A preliminary investigation on the occurrence and distribution of antibiotics in the Yellow River and its tributaries, China. Water Environ. Res. 81 (3), 248-254.

Xu, W.H. Yan, W. Li, X.D, Zou, Y.D. Chen, XX. Huang W. X, Miao, L, Zhang, R. Zhang G., Zou, S.C., 2013. Antibiotics in riverine runoff of the Pearl River Delta and Pearl River Estuary, China: concentrations, mass loading and ecological risks. Environ. Pollut. 182, 402-407.

Xu, W.H., Yan, W., Huang, W.X., Miao, L., Zhong, L.F., 2014. Endocrine-disrupting chemicals in the Pearl River Delta and coastal environment: sources, transfer, and implications. Environ. Geochem. Health 36 (6), 1095-1104.

Xue, B.M., Zhang, R.J., Wang, Y.H., Liu, X., Li, J., Zhang, G., 2013. Antibiotic contamination in a typical developing city in south China: occurrence and ecological risks in the Yongjiang River impacted by tributary discharge and anthropogenic activities. Ecotoxicol. Environ. Saf. 92, 229-236.

Yang, R., Liu, Y., Long, H., Qiao, L., 2015. Spatio-temporal characteristics of rural settlements and land use in the Bohai Rim of China. J. Geogr. Sci. 25 (5), 559-572.

Yao, L., Wang, Y., Tong, L., Li, Y., Deng, Y., Guo, W., Gan, Y., 2015. Seasonal variation of antibiotics concentration in the aquatic environment: a case study at Jianghan Plain, central China. Sci. Total Environ. 527, 56-64.

Zhang, X., Li, B., Liu, R., Zeng, P., Song, Y., Yang, Y., 2015. Identification of priority pollutants in river polluted by effluents from printing and dyeing enterprises in Taizihe Watershed. Chin. J. Environ. Eng. 9 (4), 2007-2013 (In Chinese).

Zheng, Q., Zhang, R., Wang, Y., Pan, X., Tang, J., Zhang, G., 2012. Occurrence and distribution of antibiotics in the Beibu Gulf, China: Impacts of river discharge and aquaculture activities. Mar. Environ. Res. 78, 26-33.

Zuccato, E., Castiglioni, S., Fanelli, R., 2005. Identification of the pharmaceuticals for human use contaminating the Italian aquatic environment. J. Hazard. Mater. 122 (3), 205-209. 